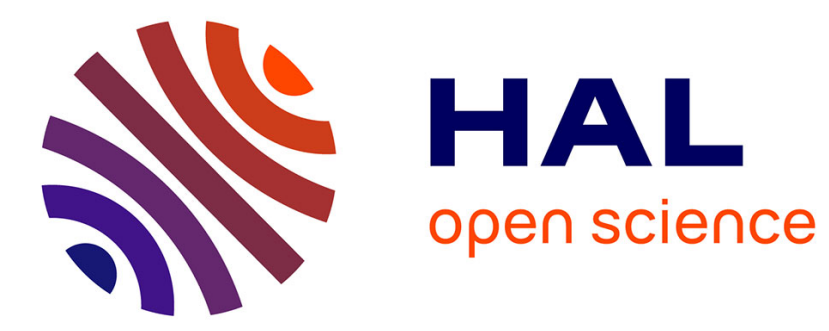

\title{
Effect of long-term physical activity practice after cardiac rehabilitation on some risk factors
}

Céline Freyssin, Philippe Blanc, Chantal Verkindt, Sébastien Maunier, Fabrice Prieur

\section{To cite this version:}

Céline Freyssin, Philippe Blanc, Chantal Verkindt, Sébastien Maunier, Fabrice Prieur. Effect of long-term physical activity practice after cardiac rehabilitation on some risk factors. International Journal of Rehabilitation Research, 2011, 34 (4), pp.357-359. 10.1097/MRR.0b013e3283498b0e . hal-01232328

\section{HAL Id: hal-01232328 \\ https://hal.univ-reunion.fr/hal-01232328}

Submitted on 3 Nov 2016

HAL is a multi-disciplinary open access archive for the deposit and dissemination of scientific research documents, whether they are published or not. The documents may come from teaching and research institutions in France or abroad, or from public or private research centers.
L'archive ouverte pluridisciplinaire HAL, est destinée au dépôt et à la diffusion de documents scientifiques de niveau recherche, publiés ou non, émanant des établissements d'enseignement et de recherche français ou étrangers, des laboratoires publics ou privés. 


\title{
Effect of long-term physical activity practice after cardiac rehabilitation on some risk factors
}

\author{
Céline Freyssin $\mathrm{Jr}^{\mathrm{a}, \mathrm{b}}$, Philippe Blanc ${ }^{\mathrm{b}}$, Chantal Verkindt ${ }^{\mathrm{a}}$, Sébastien Maunier ${ }^{\mathrm{b}}$ \\ and Fabrice Prieur ${ }^{\mathrm{c}, \mathrm{d}}$
}

The objective of this study was to evaluate the effects of long-term physical activity practice after a cardiac rehabilitation program on weight, physical capacity and arterial compliance. The Dijon Physical Activity Score was used to identify two groups: sedentary and active. Weight, distance at the 6-min walk test and the small artery elasticity indice were measured at the beginning, at the end of the rehabilitation program and at $18.3 \pm 5.3$ months after. After the cardiac rehabilitation, sedentary patients showed a significant increase in weight and a significant reduction in distance on the 6-min walk test and in the arterial compliance. Active patients did not show any alteration in these parameters. We concluded that, after a cardiac rehabilitation program, the sedentary lifestyle has a negative influence on weight, physical capacity and arterial compliance, which are major markers of risk factors. In

\section{Introduction}

The benefits of cardiac rehabilitation and exercise training programs are well documented in literature (Casillas et al., 2007), and these programs induce a significant increase in physical capacity. Numerous physiological improvements result in a better control of cardiovascular risk factors. Rehabilitation programs improve glycemia balance, reduce hypercholesterolemia, hypertension and obesity indices and therefore decrease the overall cardiovascular risk (Lavie and Milani, 2000; Casillas et al., 2007). Moreover, arterial compliance, which reflects the mechanical properties of arteries, increases significantly during a 6-week rehabilitation program, probably through improving endothelial function (Trzos et al., 2007).

Pursuing regular physical activity after a rehabilitation program seems necessary to maintain its acquired benefits, but that remains to be confirmed (Boesch et al., 2005). Although rehabilitation benefits are many and well documented, there is little information on the fate of patients after rehabilitation.

Therefore, the aim of this study was to examine the influence of maintaining the recommended physical activity after achieving a regular and continuous 6 weeks of cardiac rehabilitation on three risk factors: weight, physical capacity and arterial compliance. contrast, the practice of physical activity preserves these parameters.

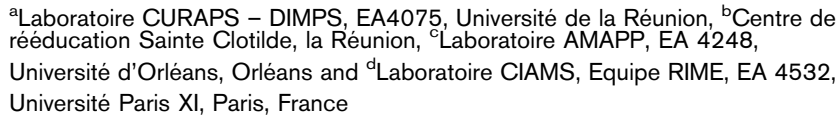
rééducation Sainte Clotilde, la Réunion, 'Laboratoire AMAPP, EA 4248, Université d'Orléans, Orléans and 'Laboratoire CIAMS, Equipe RIME, EA 4532, Université Paris XI, Paris, France

Correspondence to Céline Freyssin Jr, DIMPS - CURAPS, UFRSHE Université de la Réunion, 117, rue du Général Ailleret, 97430 Le Tampon, La Réunion, France

Tel: + 33693700631; fax: + 26202625795 71; e-mail: cfreyssin@gmail.com

\section{Methods \\ Patients}

We investigated the clinical course of 42 patients [mean age, 56.2 standard deviation $(\mathrm{SD}) \pm 10$ years; nine women and 33 men], having made their cardiac rehabilitation between January 2007 and June 2008 in a cardiac rehabilitation center. All these patients have suffered from cardiovascular diseases such as myocardial infarction and angioplasty with added risks factors such as diabetes, obesity, smoking, cholesterol and hypertension. Patients with heart failure and left ventricular ejection fraction of less than $40 \mathrm{ml}$ and patients with chronic obstructive pulmonary disease were excluded from the study. Patients were evaluated at the beginning (T0), at the end (T1) and at $18.3(\mathrm{SD}) \pm 5.3$ months after their cardiac rehabili-tation ( $\mathrm{T} 2)$.

\section{Cardiac rehabilitation program}

The patients underwent a 6-week program including physical activity and educational sessions. The physical activity consisted of $13 \mathrm{~h}$ of exercise per week conducted under the supervision of a physiotherapist or a sports teacher and nurse.

\section{Measurements}

The assessment of physical activity level after cardiac rehabilitation was performed at T2 by the Dijon Physical 
Activity Score, which is reliable for measuring physical activity in patients with stable coronary artery disease (Gremeaux et al., 2008). The Dijon Physical Activity Score was conducted following a standardized protocol and with the same staff member who asked multiple choice questions to patients.

Patients were then divided into two groups. Twenty patients who had a score of less than 10 were included in the sedentary group (SG) and 22 patients who had a score of more than 20 were included in the active group (AG). Patients with a score between 10 and 20 were excluded from further analysis.

Functional capacity was assessed using a 6-min walk test (6MWT). It was conducted following a standardized protocol described by guidelines (Brooks et al., 2003).

Small artery compliance was measured noninvasively with the pulse wave method (HDI/Pulsewave CR-2000 Research CardioVascular Profiling System; Hypertension diagnostics, Eagan, Minnesota, USA). Measurements with this device are repeatable over both short and intermediate periods of observation(Prisant $e t$ al., 2002). Measurements were taken in the morning before any physical exercise, in a partially extended position, after a 5 -min period of rest, under identical conditions.

\section{Statistical analysis}

Two-way analysis of variance with group and time as factors and a-posteriori tests (Tukey) were performed for each studied variable. Statistical significance was set at a $P$ value of less than 0.05 .

\section{Results}

At T0, no significant difference was observed between groups except for the distance calculated on the 6MW'T (SG, 448; SD, 81 months vs. AG, 513; SD, 91 months; $P=0.022)$. For $S G$, the weight was significantly higher at T2 (mean, 76.7; SD, $15.9 \mathrm{~kg}$ ) in comparison with T0 (mean, 74.8; SD, $15.5 \mathrm{~kg} ; P=0.021$ ) and in comparison with T1 (mean, 75.0; SD, $15.3 \mathrm{~kg} ; P=0.036$; Fig. 1). The distance calculated at the 6MWT was significantly higher at T1 (mean, 495; SD, 104 months) compared with T0 (mean, 448; SD, 81 months; $P=0.017$ ) for SG and tended to be higher at T1 (mean, 546; SD, 75 months) compared with T0 (mean, 513; SD, 91 months; $P=0.09$ ) for AG. For SG, this distance was significantly reduced at T2 (mean, 428; SD, 123 months) in comparison with T1 $(P<0.001)$; whereas for $\mathrm{AG}$, this distance was significantly increased at T2 (mean, 558; SD, 60 months) in comparison with T0 $(P=0.012)$. For $\mathrm{SG}$, the index of arterial compliance was significantly lower at T2 (mean, 2.7; $\mathrm{SD}, 0.9 \mathrm{ml} / \mathrm{mmHg} \times 100)$ in comparison with $\mathrm{T} 0$ (mean, 4.0; SD, $2.5 \mathrm{ml} / \mathrm{mmHg} \times 100 ; P=0.013$ ) and in comparison with T1 (mean, 4.6; SD, $2.2 \mathrm{ml} / \mathrm{mmHg} \times 100$; $P<0.001)$. At T2, this index was significantly higher for
Fig. 1
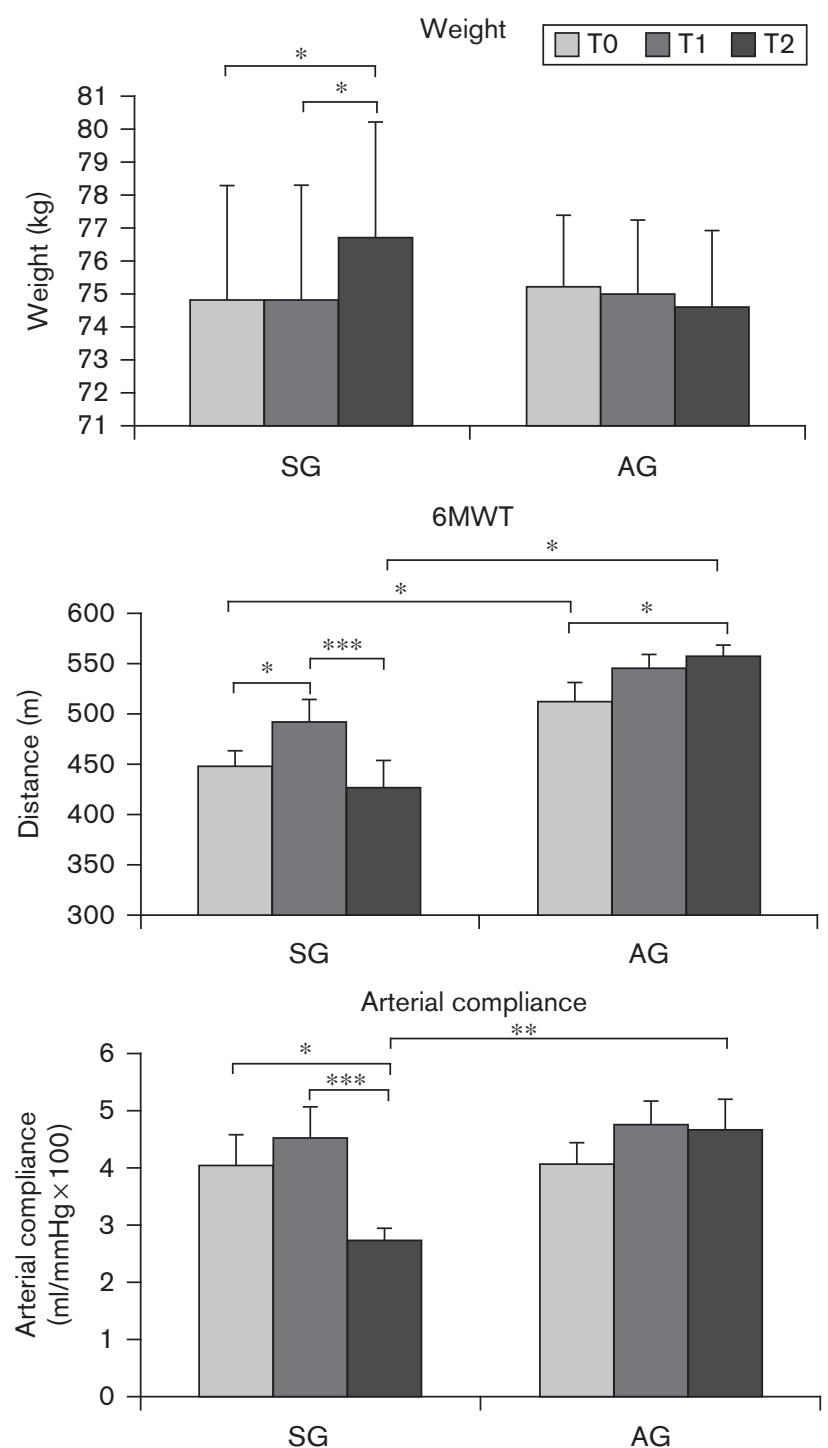

Weight, distance at the 6-min walk test (6MWT) and arterial compliance at TO, T1 and T2 for sedentary group (SG) and active group (AG). Bars represent mean, error bars represent their standard errors. $* P<0.05, * * P<0.01, * * * P<0.001$.

AG (mean, 4.6; SD, $2.6 \mathrm{ml} / \mathrm{mmHg} \times 100$ ) than for $\mathrm{SG}$ $(P=0.004)$.

\section{Discussion}

The main results of our study are that at $\mathrm{T} 2$ in comparison with $\mathrm{T} 1$, the weight was increased in $\mathrm{SG}$ but not in AG, the distance calculated at the 6MWT was decreased in $S G$ and was improved in $A G$ and, lastly, the arterial compliance was decreased in SG but not in AG.

The lack of weight increase in patients in the AG could be due to their regular practice of physical activity after rehabilitation. Despite the fact that we did not control their 
food during this 18-month period, our result is concordant with the literature and confirms that physical activity helps to stabilize weight and that the sedentary lifestyle facilitates the weight gain (Roberts and Barnard, 2005). As weight is considered to be a risk factor for cardiovascular disease, it underlines the importance of physical activity after the rehabilitation program for these patients.

With regard to the 6MWT results, the rehabilitation program improved the physical capacity in SG but not in AG (we note only a tendency for AG). The performance at the 6WMT at T0 was better for AG than for SG indicating that $\mathrm{AG}$ had a superior physical capacity than SG at the beginning of the rehabilitation program. It could explain the lack of improvement of physical capacity with rehabilitation in this group. The difference observed in the 6MWT for SG between T1 and T2 shows that a sedentary lifestyle after rehabilitation diminished the physical capacity and canceled the benefits on the physical capacity acquired during the rehabilitation program. Pursing regular physical activity allows maintenance of physical capacity and can even further improve it, as indicated by the significant increase in the distance at the 6MWT for AG between T2 and T0. As the level of physical capacity is a determinant of the overall cardiovascular health and is a predictive factor of cardiovascular mortality (Myers et al., 2002), pursuing regular physical activity after rehabilitation is of importance.

With regard to peripheral artery compliance at rest, the rehabilitation program had no influence over it for either groups (no significant change between $\mathrm{T} 0$ and T1). However, the sedentary lifestyle after rehabilitation reduced the compliance of peripheral arteries as shown by the decrease in the arterial compliance in SG at T2 compared with $\mathrm{T} 0$ and $\mathrm{T} 1$. In contrast, the fact that, for $\mathrm{AG}$, the arterial compliance was not altered at $\mathrm{T} 2$ in comparison with $\mathrm{T} 0$ and $\mathrm{T} 1$ suggests that pursuing physical activity contributed to maintaining the level of arterial compliance. The reduction of small artery elasticity is due to an endothelial dysfunction, which is highly associated with cardiovascular events (Grey et al., 2003). Indeed, endothelial dysfunction plays a key role in the development of atheroma and in the arterial blood pressure regulation (Casillas et al., 2007). Therefore, protecting the endothelium is a key element in reducing cardiovascular risk (Cohn, 2001); and regular physical activity after a rehabilitation program could contribute to this protection, as it seems to reduce endothelial dysfunction.

\section{Conclusion}

This study shows that pursuing physical activity after cardiac rehabilitation allows counteracting the worsening of cardiovascular risk factors such as weight, physical capacity and arterial compliance. Therefore, physical activity after cardiac rehabilitation must be considered central in the management of cardiovascular risk.

Further investigations are necessary to explore the impact of a quantified physical activity on a larger set of cardiovascular risk factors in patients who are suffering from different cardiovascular diseases.

\section{Acknowledgements Conflicts of interest}

There are no conflicts of interest.

\section{References}

Boesch C, Myers J, Habersaat A, llarraza H, Kottman W, Dubach P (2005), Maintenance of exercise capacity and physical activity patterns 2 years after cardiac rehabilitation. J Cardiopulm Rehabil 25:14-21; quiz 22-13

Brooks D, Solway S, Gibbons WJ (2003). ATS statement: on six-minute walk test. Am J Respir Crit Care Med 167:1287-1287.

Casillas JM, Gremeaux V, Damak S, Feki A, Perennou D (2007). Exercise training for patients with cardiovascular disease. Ann Readapt Med Phys 50: 403-418,386-402

Cohn JN (2001). Arterial compliance to stratify cardiovascular risk: more precision in therapeutic decision making. Am J Hypertens 14:258S-263S.

Gremeaux V, Lemoine Y, Fargeot A, D'Athis P, Beer JC, Laurent Y, et al. (2008). The Dijon Physical Activity Score: reproducibility and correlations with physical fitness in patients with coronary artery disease. Ann Readapt Med Phys 51:366-378.

Grey E, Bratteli C, Glasser SP, Alinder C, Finkelstein SM, Lindgren BR, et al. (2003). Reduced small artery but not large artery elasticity is an independent risk marker for cardiovascular events. Am J Hypertens 16:265-269.

Lavie CJ, Milani RV (2000). Benefits of cardiac rehabilitation and exercise training. Chest 117:5-7.

Myers J, Prakash M, Froelicher V, Do D, Partington S, Atwood JE (2002). Exercise capacity and mortality among men referred for exercise testing. $N$ Engl J Med 346:793-801.

Prisant LM, Pasi M, Jupin D, Prisant ME (2002). Assessment of repeatability and correlates of arterial compliance. Blood Press Monit 7:231-235.

Roberts CK, Barnard RJ (2005). Effects of exercise and diet on chronic disease. J Appl Physiol 98:3-30.

Trzos E, Kurpesa M, Rechcinski T, Wierzbowska-Drabik K, Krzeminska-Pakula M (2007). The influence of physical rehabilitation on arterial compliance in patients after myocardial infarction. Cardiol J 14:366-371. 